UDK 528.37

\title{
ON THE DEFINITION OF HEIGHT REFERENCE SURFACES OVER AN ARBITRARY SELECTED AREA BY MEANS OF DFHRS APPROACH
}

\author{
Perparim AMETI ${ }^{1}$, Reiner JÄGER ${ }^{2}$ \\ ${ }^{1}$ Faculty of Civil Engineering and Architecture, University of Prishtina, \\ Fakulteti teknik pn, 10000 Prishtine, Kosovo \\ ${ }^{2}$ Hochschule Karslruhe Technik und Wirtschaft Institut für Geomatik, \\ Moltkestr. 30, 76133 Karlsruhe, Germany \\ E-mails: ${ }^{1}$ perparim.ameti@uni-pr.edu (corresponding author); ${ }^{2}$ reiner.jaeger@hs-karlsruhe.de
}

Received 07 September 2016; accepted 30 November 2016

\begin{abstract}
The aim of this study is to analyze the best fitting geoid model for an arbitrary selected area of investigation. The Digital Finite Element Height Reference Surface (DFHRS) method, developed by Hochschule Karlsruhe has been chosen to define the height reference surface for the territory of Kosovo, which should be defined as national vertical datum. This approach allows the conversion of ellipsoidal heights determined by GPS into the standard heights, which refer to the height reference surface (HRS) of an orthometric, or normal surface system. The DFHRS is defined as continues HRS in arbitrary large areas by bivariate polynomials over an irregular grid (Jäger, Schneid 2001). The DFHRS approach uses wide range of the input data (Geometric and Physical) and in our case there were $30 \mathrm{GPS} /$ leveling height data as well as physical derivatives from different global geopotential models. The proposed approach has been successfully applied and results are compared to actual normal heights and in selected profiles of digital elevation reference surface calculated from the national control network. Special attention has been given to the choice of the geopotential model and the selection of the pass points in source and target surface.
\end{abstract}

Keywords: GPS, Geoid Undulation, geopotential models, leveling.

\section{Introduction}

The traditional technique of defining heights by using spirit levelling is going to be not the most efficient one, firstly, because of time consummation and second because of the required consumption costs. Nowadays, the GNSS system has been established as the basic geodetic tool in most of the surveying activities, and it serves as the most cost effective and very accurate. The basic target in the geodetic science and practice has always been a high accuracy and reliability of data with minimal cost expenses. The answer to these aspirations, has been solved by using the GNSS and specially be the establishment of the concept of networked reference GNSS stations, called Continuously Operating Reference Station (CORS). These services are usually established in national level areas and enable measurements by using GNSS in real time. Based on the measurement which can be realized in the field by GPS, the master centers of the CORS calculates the correction parameters for different levels of accuracy in real time and offer them to the users continuously. The technique of spirit leveling provides a height that is commonly known as a height above sea level surface. Additionally, with the combination of measured height differences and gravity measurements, it is possible to obtain final values of the heights that are known as orthometric heights and are related to a zero level surface (Geoid). The surface of the geoid is an equipotential surface and it is closely associated with mean sea level on a global basis (Barthelmes 2013). On the other hand, GPS, offers these three-dimensional, geometric relationships (Ellipsoidal coordinates), and in comparison to geodetic leveling, do not depend on local gravity variations. Since ellipsoidal coordinates do not directly express the notion of height related to a zero level surface (Geoid), it is necessary to transform them into above mentioned level surface. However, an approximate difference between these heights can be 
already derived from current available Global Potential Models (GPM). These models are derived from satellite measurements or combination with terrestrial, airborne and maritime data (Lemoine et al. 1998). Nowadays, such earth global gravity models become more and more detailed and accurate and, additionally, the global topography can be determined by modern satellite methods independently from the gravity field (Barthelmes 2013). These models can be much more detailed by using of various model derived quantities with independent data and models (e.g., geoid heights derived from GPS/levelling, deflections of the vertical, etc. (Pavlis et al. 2008).

\section{Main objective}

The main objective of the study is to define a zero elevation surface (geoid model) by analyzing different GP models and other available terrestrial data, manly from GPP and precise leveling. The approach developed by Hochschule Karlsruhe, called the Digital Finite Element Height Reference Surface (DFHRS) method has been chosen and many tests should be undertaken (Jäger, Schneid 2001). This approach is based on the parametric modelling and computation of height reference surfaces (HRS) from geometric and physical observation components in a hybrid adjustment approach. The access to the parametric HRS model is enabled by DFHRS data-bases, which allow the direct conversion of GNSS (ellipsoidal) heights into physical (Orthometric, Normal...) heights. DFHRS data-bases as such can be used for online GNSS-heighting in CORS networks (Jäger, Schneid 2001) allowing users

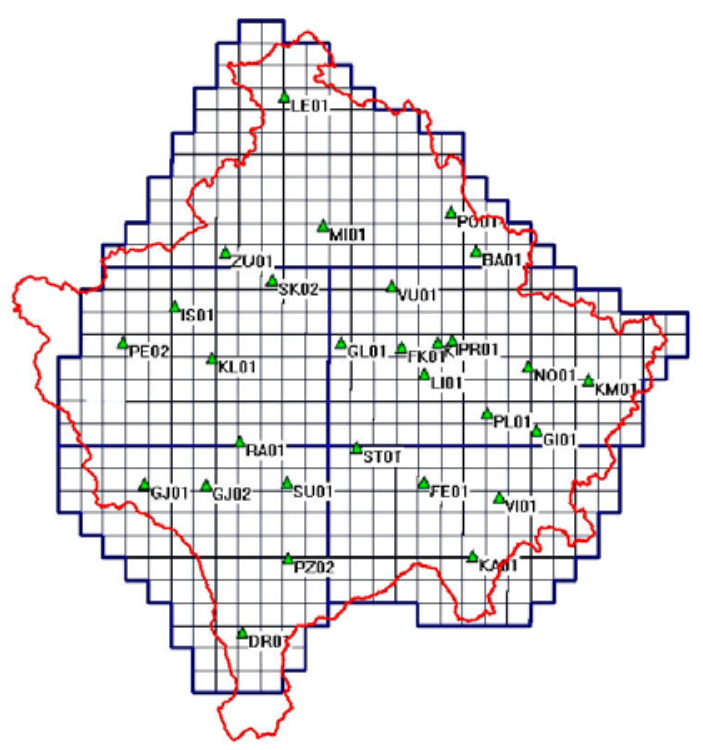

Fig. 1. GPS control network of Kosovo to get normal heights during the measurement in real time.

\section{Selected data and area of Investigation}

The whole area of the Kosovo has been used for further analysis and determination of the best solution of a height reference surface (HRS), by using DFHRS technique. Kosovo has an area of app. 11,000 km with an average altitude from $300-2500 \mathrm{~m}$ above mean sea level. For the computation of height reference surface (geoid model), 30 points of $1^{\text {st }}$ order GPS network has been chosen as target values of normal heights (Fig. 1). These points have three dimensional coordinates determined by GPS in ETRS89, as well as the height determined by precise leveling. The Kosovo 1 st order network consists of 32 points, whereby two points have been neglected from computation because of the critical deviation in the height value. After establishment of the Kosovo geodetic datum in 2001, the 1st order network has been exaggerated with additional 450 points covering whole territory of Kosovo with an approximate distance of 10 to $15 \mathrm{~km}$ between neighbor points (Kohli 2003). Currently, these points are serving as height reference surface, however their deviation in some areas exceed $\pm 50 \mathrm{~cm}$ and need to be considered.

\section{Geoid modeling approach}

For the practical use, the height $(h)$ measured directly at the Earth surface by means of GNSS it is necessary to convert into physical height $(H)$ related to a physically determined reference surface (Geoid, quasi-geoid etc.) (Tranes et al. 2007). The basic relationship between GNSS determined height and physical defined height is $N=h-H$, where $N$ stands for geoid height and represents the difference between the reference ellipsoid and the geoid $\mathrm{H}$. This formulation is the conventional approach of physical geodesy and requires the knowledge of the density of the outer masses or makes assumptions about it (Heiskanen, Moritz 1967). To avoid this issue, further we will treat Molodensky's solution for the determination of height anomaly instead of Stoke's approach to geoid undulation. The approach proposed in this study, aims to compute a Height Reference Surface (HRS), which in general, should serve as national vertical datum and specifically for real time GNSS users. In this context, the geoid separation is represented by the Finite Element Method (FEM) with polynomial parameters $p$. The DFHRS is modelled as a continues HRS in arbitrary large areas 
by bivariate polynomials over an irregular grid (Jäger, Schneid 2001).

Assuming that scale difference $(\Delta m)$ stands for an old reference surface, then the HRS is represented by the functional $N_{F E M}(p, \Delta m, \mid \lambda, \varphi, h)$ (Jäger, Schneid 2001). Imposing this functional to the basic height formula, it reads:

$$
H=h-N_{F E M}(p, \Delta m \mid \lambda, \varphi, h) .
$$

Or, respectively:

$$
H=h-N_{D F H R S}(p, \Delta m \mid \lambda, \varphi, h),
$$

where $N_{F E M}(p, \Delta m \mid \lambda, \varphi, h)$ is determined by bivariate polynomial of degree $n$, which are set up in regular meshes (Jäger, Kälber 2000). Labeling the polynomial coefficients $\left(a_{00}, a_{11} \ldots\right)$ with $p^{i}$ of the $i$-th mesh for $n$ meshes in total, the height $N_{F E M}\left(p^{i} \mid x, y\right)$ of the HRS above the reference ellipsoid is:

$$
N_{F E M}\left(p^{i} \mid x, y\right)=f(x, y)^{T} p^{i},
$$

where $P^{i}=\left[p_{j} k^{i}\right]^{T} ; j=0, n ; k=0, n$ and $f(x, y)^{T}=(1$, $\left.x, y, x^{2}, x y, y^{2}, \ldots\right)$.

The general computational principle of the DFHRS approach is to divide the whole area of a continuous HRS into an appropriate number of patches. For further calculations, sufficient points in both surfaces (at least 4 points) must be known. The patches are composed as part of the whole HRS and are divided into number of regular meshes $(5 \times 5 \mathrm{~km})$ as shown in the Figure 2.

ch patch contents a datum and related transformation parameters (d) and each mesh have HRS parameters $(p)$. The DFHRS parameters $(p)$ and the mesh information are stored in an appropriate file at data base of DFHRS software. In this approach the continuity condition has been considered, whereby, for the NFEM point in the boundary between two meshes should be depending for both meshes $\left(C_{0}\right.$-continuity) and the slope at the boundary of the meshes should represent the whole area $\left(C_{1}\right.$-continuity). The Mathematical model for the computation of the geoidal heights by using DFHRS approach includes identical points with ellipsoidal heights $(h)$ in source system and normal or orthometric $(H)$ heights in target system as well as additional physical components from global or regional geopotential models. The polynomial representation of the NFEM, can be written in terms of design matrix $\boldsymbol{f}$ and parameters vector $\boldsymbol{p}$ :

$$
N_{F E M}(p \mid x, y)=\boldsymbol{f}(x, y)^{T} \boldsymbol{p} .
$$

The mathematical model for heights in the target system can be expressed by standard formulation:

$$
H+v=H^{\prime},
$$

where $H$ - heights in target system; $H^{\prime}$ - adjusted heights in target system; $v$ - residuals.

The analogy to ellipsoidal heights reads:

$$
h^{i}+v=H-h \Delta m^{i}+N_{F E M}(\varphi, \lambda \mid p) .
$$

By using geocentric coordinate, the term $N_{F E M}$ can be written as follows:

$$
N_{F E M}(\varphi, \lambda \mid p)=N_{F E M}(X(\varphi, \lambda), Y(\varphi, \lambda) \mid p)
$$

and in terms of a bivariate polynomial it reads:

$$
N_{F E M}(\varphi, \lambda \mid p)=\sum_{i=0}^{\infty} \sum_{i=0}^{\infty} a_{i, j} x^{i} y^{i}=f(x, y)^{T} p,
$$

where: $h_{i}$ - ellipsoidal height in ith mash; $v$ - residuals; $H$ - height in the target system; $\Delta m^{i}$ - scale difference factor; $f(x, y)^{T}$ - coefficients of polynomial function; $p$ - parameters of polynomial function.

Geoid height form global geopotential models can be expressed as follows:

$$
N_{G P M}^{i}+v=f(x, y)^{T} \cdot p+\partial N_{G}\left(d^{j}\right),
$$

where, $N_{G P M}^{i}$ is geoid height from GPM in the $j$-th mash and $\partial N_{G}\left(d^{j}\right)$ is datum transition parametrization of the geoid height in the $j$-th patch.

Other physical parameters, which have been derived from global potential models, are deflections of vertical. The appropriate mathematical model reads:

$$
\begin{gathered}
\xi^{j}+v=-f_{\varphi}^{T} /(M(\varphi)+h) p+\partial \xi\left(d_{\xi}^{j}\right) \\
\left.\eta^{j}+v=-f_{\lambda}^{T} /[N(\varphi)+h) \cos (\varphi)\right] p+\partial \eta\left(d_{\eta}^{j}\right) .
\end{gathered}
$$

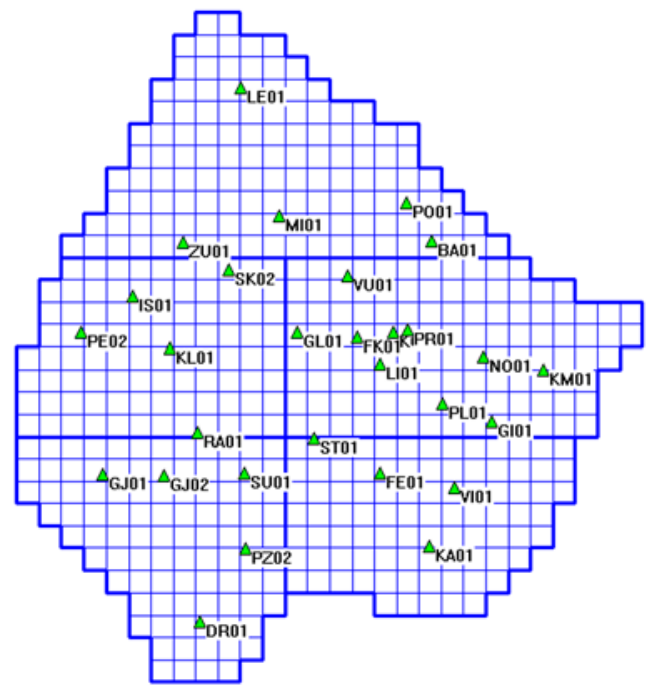

Fig. 2. Definition of patches and mashes for the selected area of investigation 
Whereby, $\xi^{j}$ is North-South component of the vertical deflection in the $j$-th mash and $\eta^{j}$ is the WestEast component of the deflection of vertical in the $j$-th mash.

- $f_{\varphi}^{T}$ and $f_{\lambda}^{T}$ are polynomial functions in the latitude/longitude.

$-M, N$ are radius of curvature in the meridian/ prime vertical.

$-\partial \xi\left(d_{\xi}^{j}\right), \partial \eta\left(d_{\eta}^{j}\right)$ are datum transition parametrization in the deflection of vertical components.

In order to reduce the effect of medium or longwave length, systematic shape deflections in the observatis $\mathrm{N}$ and in the components of the deflection of vertical derived from GPM or other sources, the DFHRS concept predicts subdivision of any geoid model into a number of so called geoid patches, see Figure 2. The DFHRS concept foresees the continuity between neighboring meshes in order to predict a uniform height reference surface which is consistent over whole area.

\section{Geoid analyses and results}

For the computation of Kosovo geoid model, 30 points of Kosovo $1^{\text {st }}$ order network has been used. These points have known ellipsoidal coordinates in the ETR89 as well as normal heights from precise leveling network of Kosovo. The physical components of the gravity are derived from global geopotential models (EGM2008, EGM96, EGG97 and EIGEN05). For the quality control of the calculated surface, selected number of the 1st order network has been used. Additional test has been done in order to define the necessity of the determination of the vertical datum by taking into account reference surface modeling, for this purpose, a DEM was built by more than 450 points of geodetic control networks and then compared with determined geoid model. The whole area was divided into a grid of regular meshes of size $5 \times 5 \mathrm{~km}$ within the latitudes $42.00-43.25$ and longitudes $20.00-22$ east of
Greenwich. Intending to avoid possible systematic errors, 5 patches with an a-priory accuracy of $1 \mathrm{~cm}$, were used to avoid long and medium wave components in the different regional areas (Ghadi 2013). Table 1 shows the comparison of geoidal heights with the actual heights determined by GPS/leveling. Analyzing the table, we can conclude that the GPM EGM2008 (Pavlis et al. 2008) and EGG97 (Denker, Torge 1998) provided best results in comparison to EGM96 (Lemoine et al. 1998) and EIGEN05 (Förste et al. 2007). Interpreting the Table 1, results have provided an equal standard deviation when using the EGM2008 and EGG97 geopotential model $(\mathrm{Std}=0.03 \mathrm{~cm})$.

Table 1. Geoid height residuals to GPS/Leveling points

\begin{tabular}{|l|c|c|c|c|}
\hline & $\begin{array}{c}\text { GPS- } \\
\text { EGG97 }\end{array}$ & $\begin{array}{c}\text { GPS- } \\
\text { EGM96 }\end{array}$ & $\begin{array}{c}\text { GPS- } \\
\text { EGM2008 }\end{array}$ & $\begin{array}{c}\text { GPS- } \\
\text { EIGEN05 }\end{array}$ \\
\hline Points & 30 & 30 & 30 & 30 \\
\hline $\begin{array}{l}\text { Minimum } \\
(\mathrm{m})\end{array}$ & -0.05 & -0.12 & -0.05 & -0.07 \\
\hline $\begin{array}{l}\text { Maximum } \\
(\mathrm{m})\end{array}$ & 0.07 & 0.12 & 0.07 & 0.14 \\
\hline Mean (m) & 0.00 & 0.00 & 0.00 & 0.00 \\
\hline $\begin{array}{l}\text { Standard de- } \\
\text { viation (m) }\end{array}$ & 0.03 & 0.05 & 0.03 & 0.04 \\
\hline
\end{tabular}

Table 1 presents a statistical summary of the residual geoid height values obtained by using different GPM in the DFHRS approach. The EGM2008 and EGG97 models offer very good accuracy and we can clearly identify that only 5 of 30 points exceed the accuracy value of $0.04 \mathrm{~cm}$. The rest of 25 points have been determined with an accuracy of better than $4 \mathrm{~cm}$ and they cover the majority of the whole area.

Figure 4 shows residual values of geoid height computed by using all geopotential models (EGM2008. EGG97, EGM96, EIGEN05). A prevail of large deviation of residual values when using EGM96 or EIGEN05 is evident. In other side the results coming from the EGM2008 and EGG97 lies close to each other.

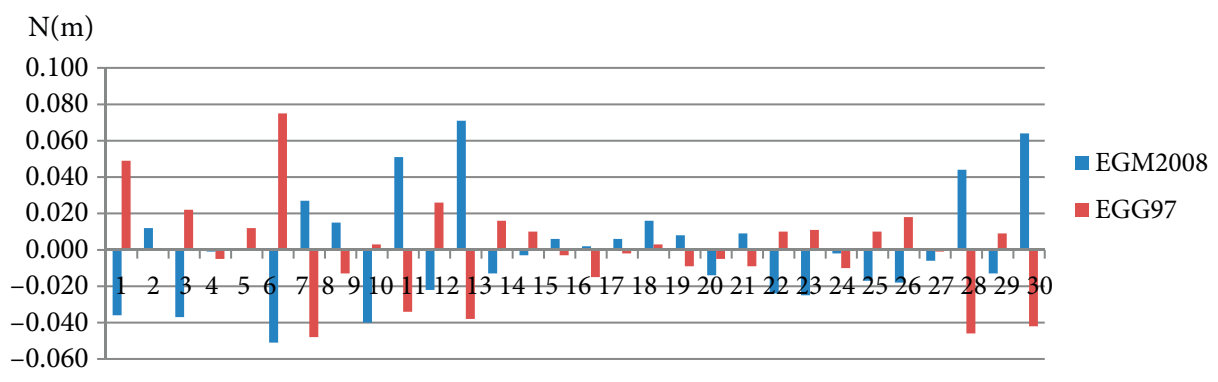

Fig. 3. Residual geoidal heights $\mathrm{N}$ over first order network points (30) 


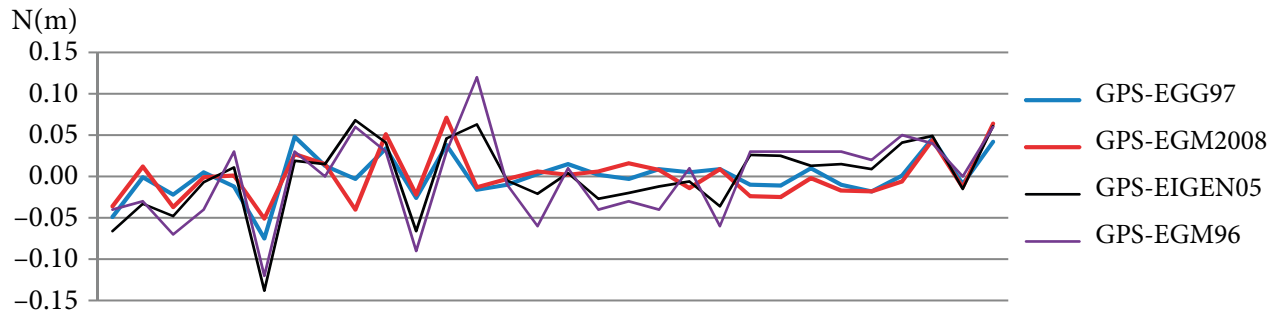

Fig. 4. Geoid height residuals to GPS/Leveling points

The difference between the geoid model calculated from EGM2008 and the geoid model calculated from EGG97 is smaller than $\pm 3 \mathrm{~cm}$. The difference model doesn't show any coherent reason for this deviation (see Figs 3 and 5).

This deviation may possibly be reason by the lack of the terrestrial data used during the determination of both above mentioned global potential models and the representation of the gravity field contains only long-wave characteristics. The difference itself of the global potential model EGM2008 and EGG97 for the territory of Kosovo has been extracted and analyzed; calculation tests yielded a difference of range appr. $1 \mathrm{~m}$.

The EGM2008 has been selected for the final solution of Kosovo geoid model (Fig. 6), even it has similar statistical accuracy with EGG97. Analyses have acknowledged that EGM2008 fits better with the topographic dispersion over the territory of Kosovo. The final HRS as such can be considered as accurate enough and can be imposed as the height reference model in the Kosovo positioning online system (KOPOS).

For the visual demonstration of differences of geoid heights by using different geopotential models,

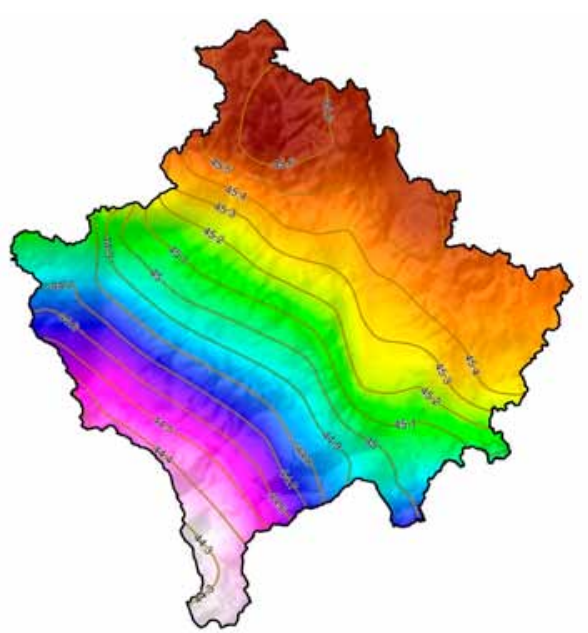

Fig. 6. Final Kosovo geoid model determined by DFHRS concept it has been chosen 6 profiles (Fig. 7) in different latitudes. Figures 8 to 13, show the flow of differences of geoid heights in different latitudes. This analysis is important only to show the necessity for the substitution of previously used model with the new model in order to achieve better accuracy in the determination of the orthometric heights by using GPS within the CORS services.

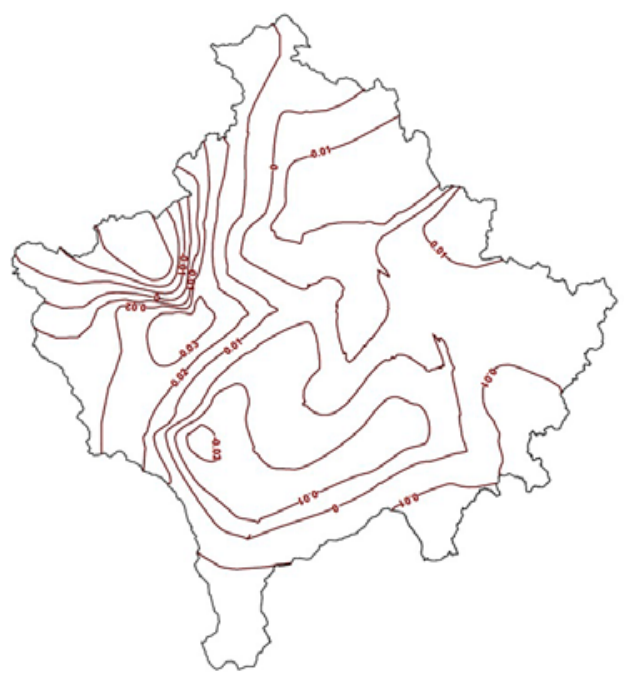

Fig. 5. Difference model (In meters) calculated from EGM2008 and EGG97

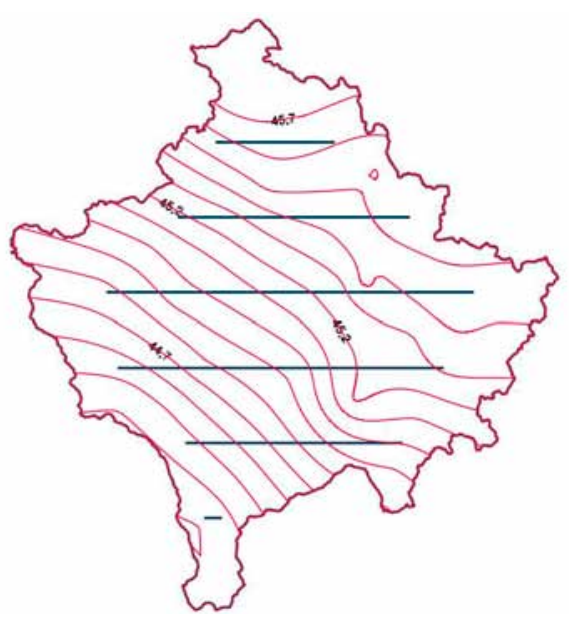

Fig. 7. Final Kosovo geoid model determined by DFHRS concept 


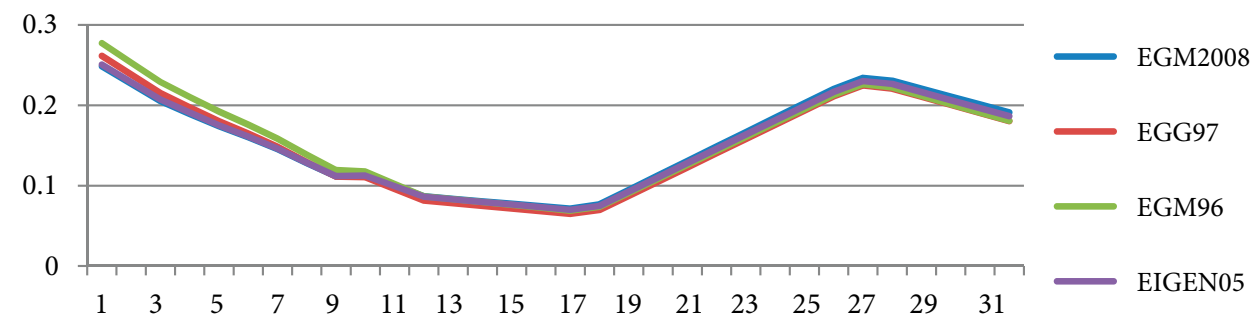

Fig. 8. Deviation of geoid heights $\mathrm{N}(\mathrm{m})$ from actual DEM a latitude 42.90

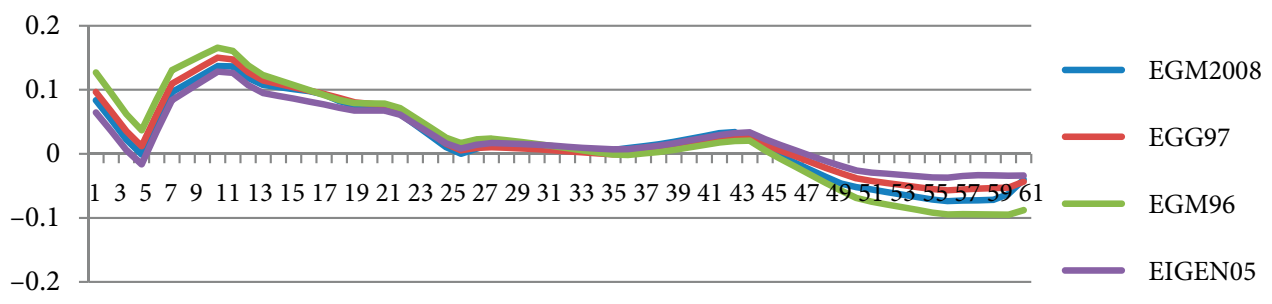

Fig. 9. Deviation of geoid heights $\mathrm{N}(\mathrm{m})$ from actual DEM a latitude 42.75

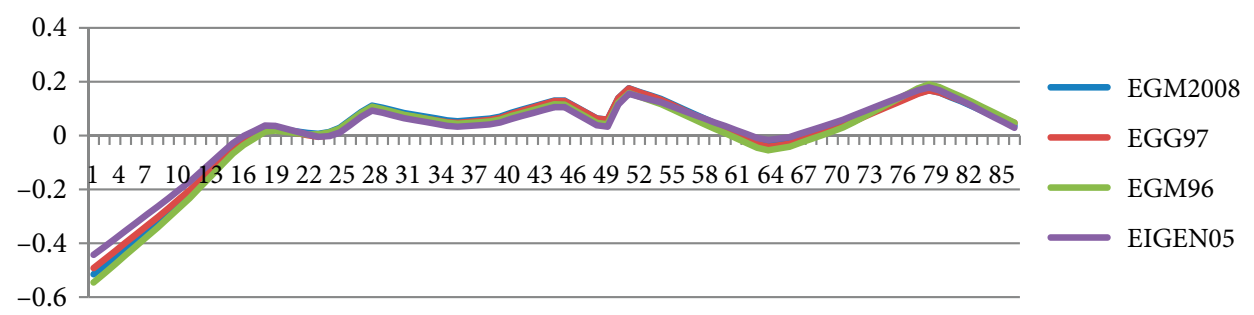

Fig. 10. Deviation of geoid heights $\mathrm{N}(\mathrm{m})$ from actual DEM a latitude 42.60

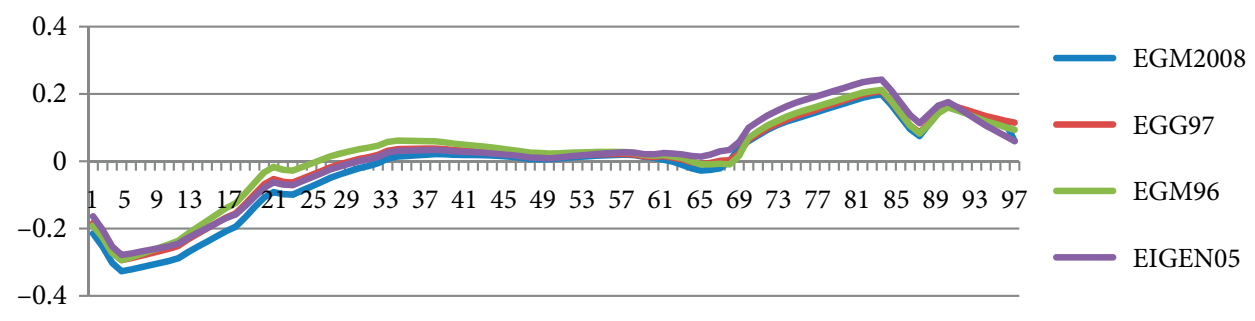

Fig. 11. Deviation of geoid heights $\mathrm{N}(\mathrm{m})$ from actual DEM a latitude 42.45

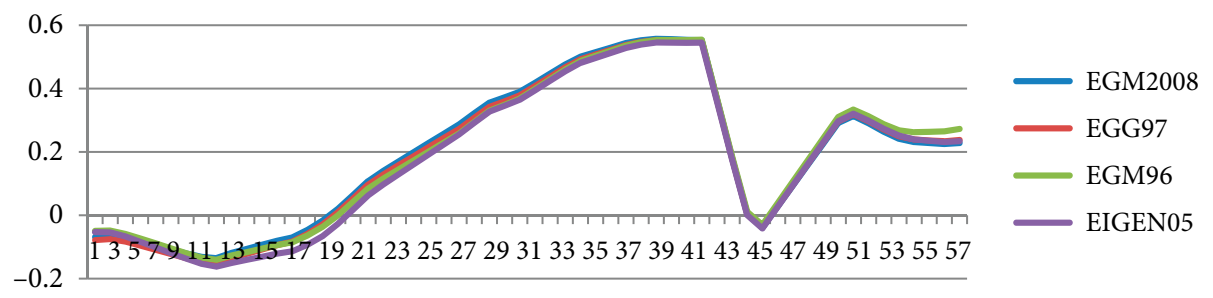

Fig. 12. Deviation of geoid heights $\mathrm{N}(\mathrm{m})$ from actual DEM a latitude 42.30

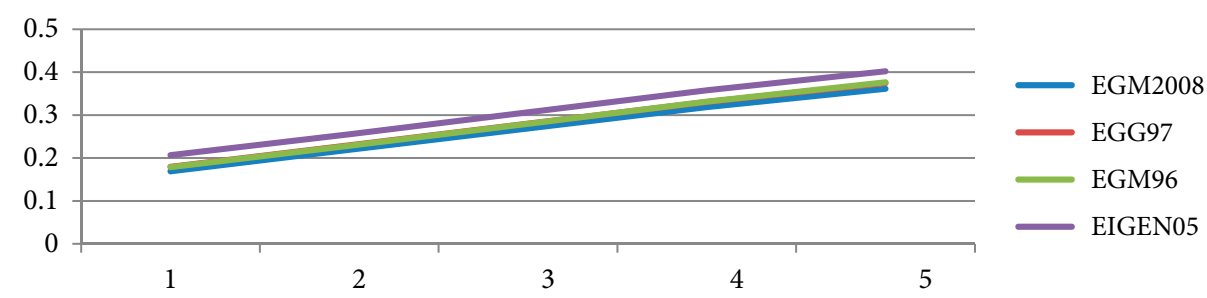

Fig. 13. Deviation of geoid heights $\mathrm{N}(\mathrm{m})$ from actual DEM a latitude 42.15 


\section{Conclusions}

This study targeted to define a high-accuracy solution for the height reference surface in order to formally state it as national vertical datum and enabling the possibility to use this surface as geoid model for GNSS or KOPOS users. To achieve this objective, a DFHRS concept has been used and 4 global geopotential models are analyzed. The best accuracy of the final model is realized by imposing the EGM2008 and EGG97. The performance of the proposed DFHRS method is evaluated during the tests with above mentioned geopotential models and GPS/Leveling heights. In these tests, achieved results in terms of geoid height are compared. The experimental results indicate that the standard deviations of the final geoid model calculated by EGM2008 and EGG97 remain identic. The standard deviations in both models are not identical in same points. This difference has not any logical continuity and must be treated in the future, especially with next gravity campaign. The global potential model EGM96 and EIGEN05 are not treated further since their deviations exceed the expected accuracy. The final solution of the geoid model for Kosovo offers an accuracy of $1-3 \mathrm{~cm}$ in most of the territory and in the mountains the standard deviation occurs from 4 to $7 \mathrm{~cm}$. In order to justify the necessity of computation of new national reference system, the new results of geoid heights has been compared with the actual Digital Elevation Model (DEM). The differences between the elevation calculated in the final geoid model and the recently used height reference surface arise up to $\pm 50 \mathrm{~cm}$. This exceeds the expectation of using new established online country-wide GPS services system in Kosovo (KOPOS) for determination of orthometric heights.

\section{References}

Barthelmes, F. 2013. Definition of functionals of the geopotential and their calculation from spherical harmonic models. GFZ Potsdam Scientific Technical Report STR09/02.

Denker, H.; Torge, W. 1998. The European gravimetric quasigeoid EGG97 - an IAG supported continental enterprise, in R. Forsberg, M. Feissel, R. Dietrich (Eds.). Geodesy on the move - gravity, geoid, geodynamics and Antarctica. IAG Symp. 119: 249-254. Berlin, Heidelberg, New York: Springer Verlag.

Förste, C.; Flechtner, F.; Schmidt, R.; Stubenvoll, R.; Rothacher, M.; Kusche, J.; Neumayer, H.; Biancale, R.; Lemoine, J. M.; Loyer, S.; Barthelmes, F.; Bruinsma, S.; König,ĀR.; Meyer, U. 2007. EIGEN-05C - a new global mean Gravity Field Model from Combination of Satellite Mission and Altimetry/ Gravimetry Surface data, in Geophysical research abstracts, Vol. 9, 04148. General Assembly European Geosciences Union (EGU), Vienna, Austria.
Ghadi, Y. 2013. Regional gravity field modeling with adjusted spherical cap harmonics in an integrated approach: Dissertation, TU Darmstadt.

Heiskanen, W.; Moritz, H. 1967. Physical geodesy. W. H. Freeman and Company, San Francisco, 291-292.

Jäger, R.; Kälber, S. 2000. Konzepte und Softwareentwicklungen für aktuelle Aufgabenstellungen für GPS und Landesvermessung. DVW Mitteilungen, Landesverein Baden-Württemberg.

Jäger, R.; Schneid, S. 2001. Online and postprocessed GPSheighting based on the concept of a digital height reference surface (DFHRS), in Vertical reference systems, IAG Sympozium, February 2001, Cartagena, Colombia, 124: 203-208. Springer, Heidelberg.

Kohli, A. 2003. Height determination for KOSOVAREF01. Kosovo Cadastral Agency Technical Report No. 020-033, V.3.0.

Lemoine, F. G.; Kenyon, S. C.; Factor, J. K.; Trimmer, R. G.; Pavlis, N. K.; Chinn, D. S.; Cox, C.; Klosko, S. M.; Luthcke, S. B.; Torrence, M. H.; Wang, Y. M.; Williamson, R. G.; Pavlis, E. C.; Rapp, R. H.; Olson, T. R. 1998. The development of the join NASA GSFC and NIMA geopotential model EGM96, NASA Technical Paper No. 1998-206861.

Pavlis, N.K.; Holmes, S. A.; Kenyon, S. C.; Factor, J. K. 2008. An Earth Gravitational Model to Degree 2160: EGM2008, presented at the 2008 General Assembly of the European Geosciences Union, April 13-18 2008, Vienna, Austria.

Tranes, M. D.; Meyer, T. H.; Massalski, D. 2007. Comparisons of GPS-derived orthometric heights using local geometric geoid models, Journal of Surveying Engineering 133(1): 6-13. https://doi.org/10.1061/(ASCE)0733-9453(2007)133:1(6)

Perparim AMETI is Dr, an Associate Professor at University of Prishtina, He has been working at Labor for GNSS and Navigation at Karlsruhe University of applied sciences from March to September 2015. His main research area is in the field of lo$\mathrm{cal}$ and regional geoid modelling. Dr Ameti has the $\mathrm{PhD}$ from Darmstadt University of Technology, Research experience from German National Centre of Geosciences (GFZ) in Potsdam, Germany and Ohio State University, USA.

Reiner JÄGER is Dr, University Professor at Karlsruhe University of Applied Sciences, Germany. He is director of the Institute of Geomatics at the Institute of Applied Research (IAF), head of Laboratory of GNSS \& Navigation, and head of the international study program Geomatics (MSc). Further he is leading many international projects in the field of GNSS, navigation, gravity field determination and other geodetic research fields. 